\title{
Coconut coir activated carbon: an adsorbent for removal of lead from aqueous solution
}

\author{
M. Chaudhuri \& S. N. B. Saminal \\ Department of Civil Engineering, \\ Universiti Teknologi PETRONAS, Malaysia
}

\begin{abstract}
The purpose of this study was to prepare activated carbon from an agricultural solid waste and assess its effectiveness in adsorptive removal of lead from aqueous solution. Activated carbon was prepared from coconut coir and its characteristics were compared with that of a commercial bituminous coal-based activated carbon. The coconut coir activated carbon possessed higher surface and micropore areas, micropore volume and average pore diameter, and well developed meso- and micropores. Adsorption of lead from aqueous solution by the coconut coir activated carbon was examined. Batch adsorption test showed that extent of adsorption was dependent on lead concentration, contact time, $\mathrm{pH}$ and activated carbon dose. Adsorption was low at acidic $\mathrm{pH}$ and increased up to $\mathrm{pH} 5$, with marginal increase up to $\mathrm{pH} 6$. Equilibrium adsorption was attained in $2.5 \mathrm{~h}$. Lead adsorption followed pseudo-second order kinetics. Equilibrium lead adsorption data for the coconut coir activated carbon and commercial activated carbon were described by the Langmuir and Freundlich isotherm models. Coconut coir activated carbon showed higher lead adsorption capacity [7.75 (Langmuir) and 3.63 (Freundlich)] compared with the commercial activated carbon [7.55 (Langmuir) and 1.87 (Freundlich)]. Coconut coir activated carbon is a suitable substitute for commercial activated carbon in the adsorptive removal of lead from water.
\end{abstract}

Keywords: adsorption, activated carbon, coconut coir, heavy metal, lead.

\section{Introduction}

Toxic heavy metals have become an ecotoxicological hazard of prime interest and increasing significance owing to their tendency to accumulate in living 
organisms [1]. Lead is found in wastewater from industries such as battery, ceramic and glass manufacturing, metal plating and finishing, printing and tanning, and production of lead additives from gasoline [2]. The techniques to remove lead from water include ion exchange, chemical precipitation, reverse osmosis, evaporation, membrane filtration and adsorption [3]. Adsorption by activated carbon is a promising technique as it enables the removal of trace amount of lead. However, high cost of commercial activated carbon limits its use in developing countries and there is a growing need to prepare activated carbon from locally available waste materials.

Coconut coir is a residue in the processing of coconut and is an agricultural solid waste. It is rich in lignin (16-45\%), hemicellulose (24-47\%) and pectin $(2 \%)$ content $[4,5]$. The carboxylate and phenolic groups of lignin, hemicellulose and pectin are known as the main sites of metal binding [5]. In this study, activated carbon was prepared from coconut coir and its characteristics were compared with that of a commercial bituminous coal-based activated carbon. Adsorption of lead from aqueous solution by the coconut coir activated carbon was examined and its lead adsorption capacity was compared with that of the commercial activated carbon.

\section{Materials and methods}

\subsection{Activated carbon}

Coconut coir activated carbon (CCAC) was prepared by soaking washed and dried coconut coir overnight in $10 \%$ potassium hydroxide solution followed by washing with distilled water to remove free potassium hydroxide and drying at $105 \pm 5^{\circ} \mathrm{C}$ for $24 \mathrm{~h}$. It was then subjected to activation at $900^{\circ} \mathrm{C}$ for $30 \mathrm{~min}$ in an atmosphere of nitrogen. The carbon obtained was washed with distilled water and then with $10 \%$ hydrochloric acid. The carbon was washed further with distilled water to remove the free acid and dried at $105 \pm 5^{\circ} \mathrm{C}$ for $24 \mathrm{~h}$. The carbon was ground to a finer size of 212-500 $\mu \mathrm{m}$ and used in adsorption test.

A commercial bituminous coal-based activated carbon was obtained from the Calgon Carbon Corporation, Pittsburgh, PA. It was ground to a size of 212-500 $\mu \mathrm{m}$ and used in adsorption test.

\subsection{Adsorption test}

Batch adsorption test was carried out by shaking $25 \mathrm{~mL}$ of lead nitrate $\left[\mathrm{Pb}\left(\mathrm{NO}_{3}\right)_{2}\right]$ solution with $0.1 \mathrm{~g}$ of activated carbon in a stoppered glass bottle placed on an orbital shaker at $150 \mathrm{rpm}$ and room temperature $\left(22^{\circ} \mathrm{C}\right)$. After a predetermined contact time, the bottle was removed from the shaker and the supernatant was filtered through Whatman No. 1 filter paper and analysed for lead concentration by Method $3111 \mathrm{~B}$ of Standard Methods [6]. The effect of $\mathrm{pH}$ (1-6), contact time (0-180 min), lead concentration (20-60 $\mathrm{mg} \mathrm{Pb} / \mathrm{L})$, and activated carbon dose (2-10 g/L) on adsorption was evaluated. Adsorption isotherm was determined by batch equilibrium test at the optimum $\mathrm{pH}$ and 
contact time for adsorption with $25 \mathrm{~mL}$ of $10-100 \mathrm{mg} \mathrm{Pb} / \mathrm{L}$ lead solution and $0.1 \mathrm{~g}$ activated carbon.

\section{Results and discussion}

\subsection{Activated carbon characteristics}

The coconut coir activated carbon (CCAC) and commercial activated carbon (CAC) were characterised for various physical and chemical parameters, as shown in table 1. The CCAC possessed higher surface and micropore areas, micropore volume and average pore diameter than those of CAC. According to scanning electron micrograph, as shown in fig.1, the CCAC contained welldeveloped meso- and micropores compared to CAC.

Table 1: $\quad$ Characteristics of CCAC and CAC.

\begin{tabular}{|c|c|c|}
\hline Parameter & CCAC & CAC \\
\hline Surface Area $\left(\mathrm{m}^{2} / \mathrm{g}\right)$ & 826 & 626 \\
\hline Micropore Area $\left(\mathrm{m}^{2} / \mathrm{g}\right)$ & 551 & 509 \\
\hline Micropore Volume $(\mathrm{mL} / \mathrm{g})$ & 0.25 & 0.23 \\
\hline Average Pore Diameter $(\AA)$ & 24 & 15 \\
\hline Ash Content $(\%)$ & 14 & 22 \\
\hline Bulk Density $(\mathrm{g} / \mathrm{mL})$ & 0.31 & 0.52 \\
\hline $\mathrm{pH}$ & 4.3 & 5.6 \\
\hline
\end{tabular}

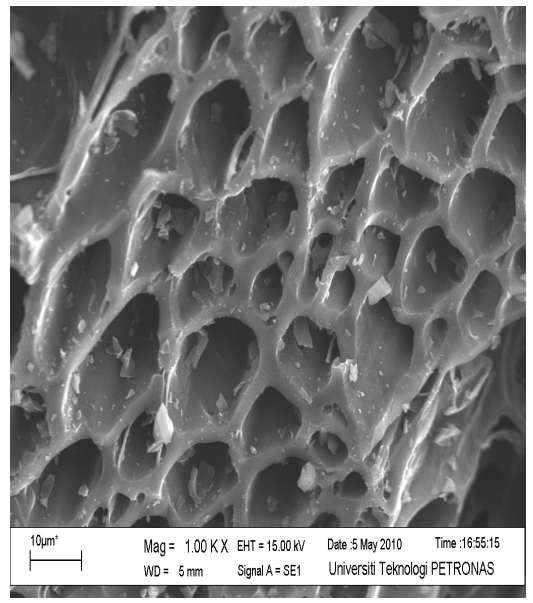

CCAC

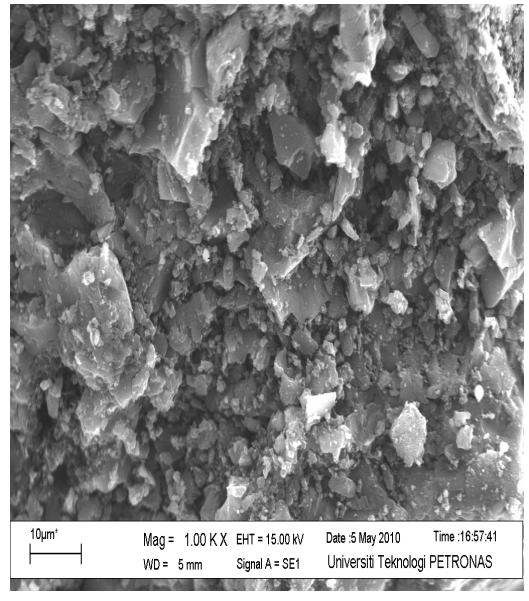

CAC

Figure 1: $\quad$ Scanning electron micrograph of CCAC and CAC. 


\subsection{Effect of pH on adsorption}

Effect of $\mathrm{pH}$ on lead adsorption by CCAC from a $20 \mathrm{mg} \mathrm{Pb} / \mathrm{L}$ lead solution in $24 \mathrm{~h}$ is shown in fig. 2. It is observed that adsorption was low at low acidic $\mathrm{pH}$ and increased (39.6\%) up to $\mathrm{pH} \mathrm{5,} \mathrm{with} \mathrm{marginal} \mathrm{increase} \mathrm{up} \mathrm{to} \mathrm{pH}$ 6. Above $\mathrm{pH} 6$, lead hydroxyl complexes and lead hydroxide form and hence was not considered. For adsorption of lead by CAC, maximum adsorption (33.2\%) also occurred at $\mathrm{pH} 5$ (data not shown). At low acidic $\mathrm{pH}$, lead adsorption was hindered possibly as a result of competition between hydrogen and lead ions for adsorption sites, with an apparent preponderance of hydrogen ions. As $\mathrm{pH}$ increased, negative charge density on the activated carbon surface increased due to deprotonation of adsorption sites, thus lead adsorption increased. Similar observations have been reported for adsorption of lead by activated carbon prepared from palm shell [7], Militia ferruginea plant leave [8], sugar cane bagasse and eucalyptus sawdust [9] and coconut shell and palm seed hull [10], and activated biochar prepared from pinewood and rice husk [11]. All subsequent adsorption tests were conducted at $\mathrm{pH} 5$.

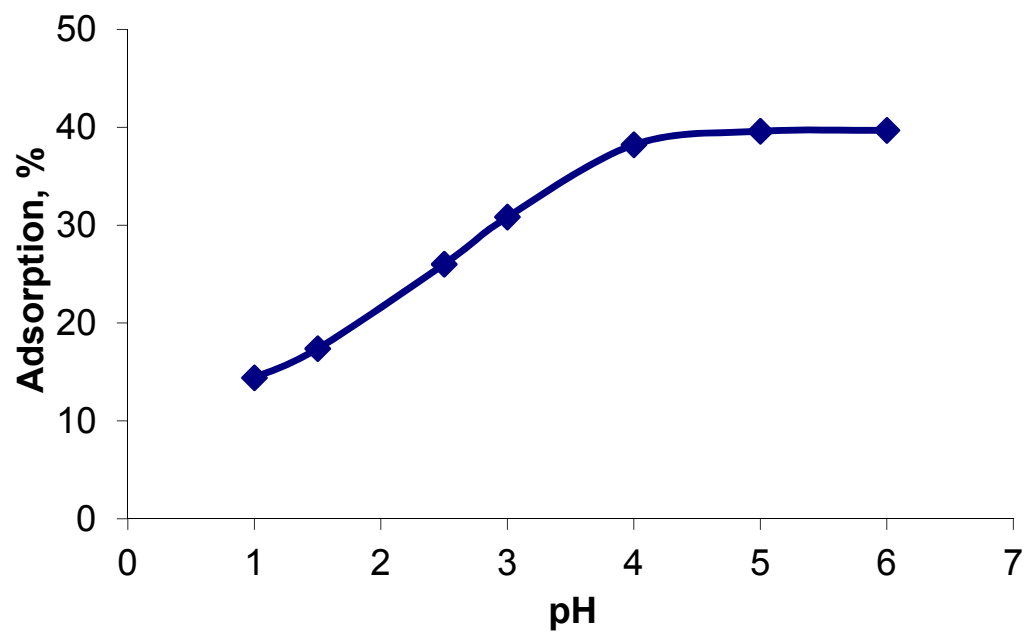

Figure 2: $\quad$ Effect of $\mathrm{pH}$ on lead adsorption by CCAC.

\subsection{Effect of contact time and lead concentration on adsorption}

Effect of contact time and lead concentration on lead adsorption by CCAC are shown in fig. 3. Extent of adsorption increased with decrease in lead concentration and increase in contact time. Equilibrium adsorption was attained in $150 \mathrm{~min}(2.5 \mathrm{~h})$. For lead adsorption by CAC, equilibrium adsorption was also attained in $2.5 \mathrm{~h}$ (data not shown). A contact time of $2.5 \mathrm{~h}$ was used in all subsequent adsorption tests. 


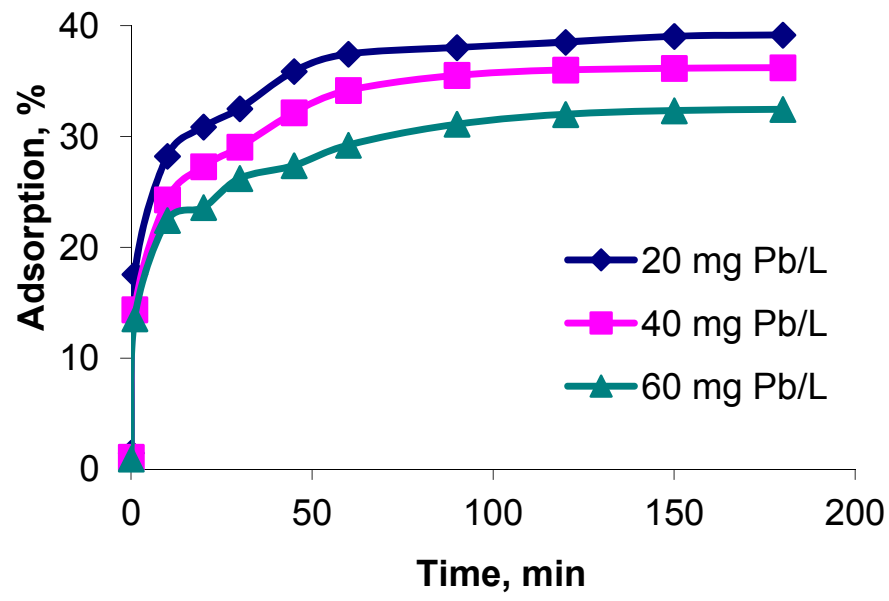

Figure 3: Effect of contact time and lead concentration on lead adsorption by CCAC.

\subsection{Effect of activated carbon dose on adsorption}

Effect of activated carbon dose on lead adsorption from a $20 \mathrm{mg} \mathrm{Pb} / \mathrm{L}$ lead solution by CCAC is shown in fig. 4. Adsorption increased with activated carbon dose and attained maximum adsorption (ca 100\%) at $8 \mathrm{~g} / \mathrm{L}$ activated carbon dose.

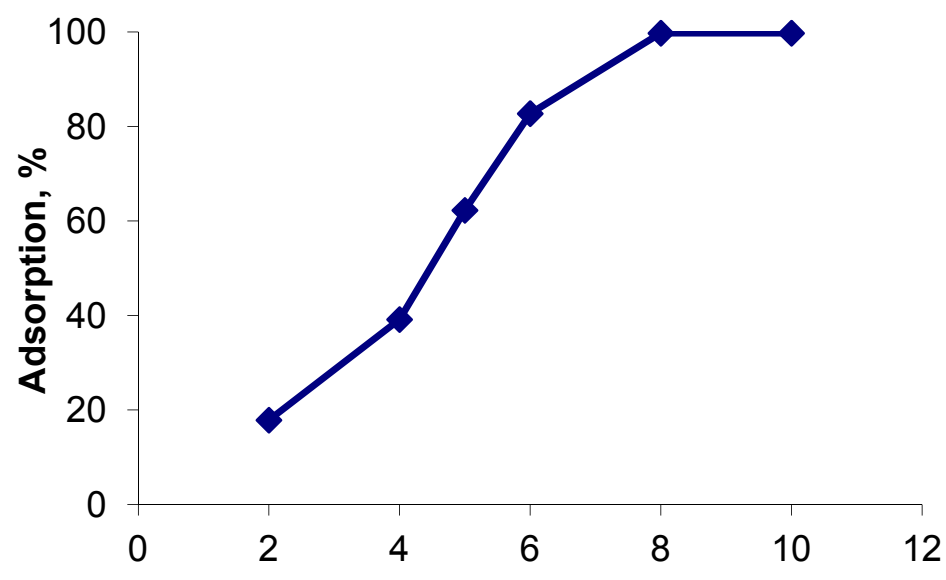

Activated carbon dose, $\mathrm{g} / \mathrm{L}$

Figure 4: Effect of activated carbon dose on lead adsorption by CCAC. 


\subsection{Adsorption kinetics}

To identify the kinetics of lead adsorption by CCAC, two commonly used kinetic models i.e. pseudo first-order and pseudo second-order [12] were employed.

$$
\begin{aligned}
& \frac{d q}{d t}=k_{1}\left(q_{e}-q\right) \\
& \frac{d q}{d t}=k_{2}\left(q_{e}-q\right)^{2}
\end{aligned}
$$

where, $q_{e}$ is the amount of solute adsorbed at equilibrium per unit weight of adsorbent $(\mathrm{mg} / \mathrm{g}), q$ is the amount of solute adsorbed at time $t$ per unit weight of adsorbent $(\mathrm{mg} / \mathrm{g})$, and $k_{1}$ and $k_{2}$ are reaction rate constants. The following linearised time dependent functions were obtained by integrating and rearranging eqns. (1) and (2) for the boundary conditions $t=0$ to $>0$ and $q=0$ to $>0$.

$$
\begin{gathered}
\log \left(q_{e}-q\right)=\ln q_{e}-\frac{k_{1} t}{2.303} \\
\frac{t}{q}=\frac{1}{k_{2} q_{e}^{2}}+\frac{t}{q_{e}}
\end{gathered}
$$

For pseudo first-order and pseudo second-order kinetic models, the reaction rate constants calculated from eqns. (3) and (4) are shown in table 2 and the kinetic plots are shown in fig. 5 and $6 . \mathrm{R}^{2}$ values as well as figs. 5 and 6 indicate that kinetics of lead adsorption by CCAC is better expressed by the pseudo second-order kinetic model. Compliance to the pseudo second-order kinetic model strongly suggests chemical adsorption or chemisorption between lead and CCAC.

Table 2: $\quad$ Pseudo first-order and pseudo second-order reaction rate constants for lead adsorption by CCAC.

\begin{tabular}{|c|l|c|c|c|}
\hline \multirow{2}{*}{$\begin{array}{c}\text { Lead concentration } \\
(\mathrm{mg} \mathrm{Pb} / \mathrm{L})\end{array}$} & \multicolumn{2}{|c|}{ Pseudo first-order } & \multicolumn{2}{c|}{ Pseudo second-order } \\
\cline { 2 - 5 } & $k_{1}\left(\mathrm{~h}^{-}\right)$ & $\mathrm{R}^{2}$ & $k_{2}(\mathrm{~g} / \mathrm{mg} \cdot \mathrm{h})$ & $\mathrm{R}^{2}$ \\
\hline 20 & 0.033 & 0.9561 & 0.027 & 0.9991 \\
\hline 40 & 0.026 & 0.9327 & 0.022 & 0.9984 \\
\hline 60 & 0.027 & 0.9571 & 0.023 & 0.9978 \\
\hline
\end{tabular}




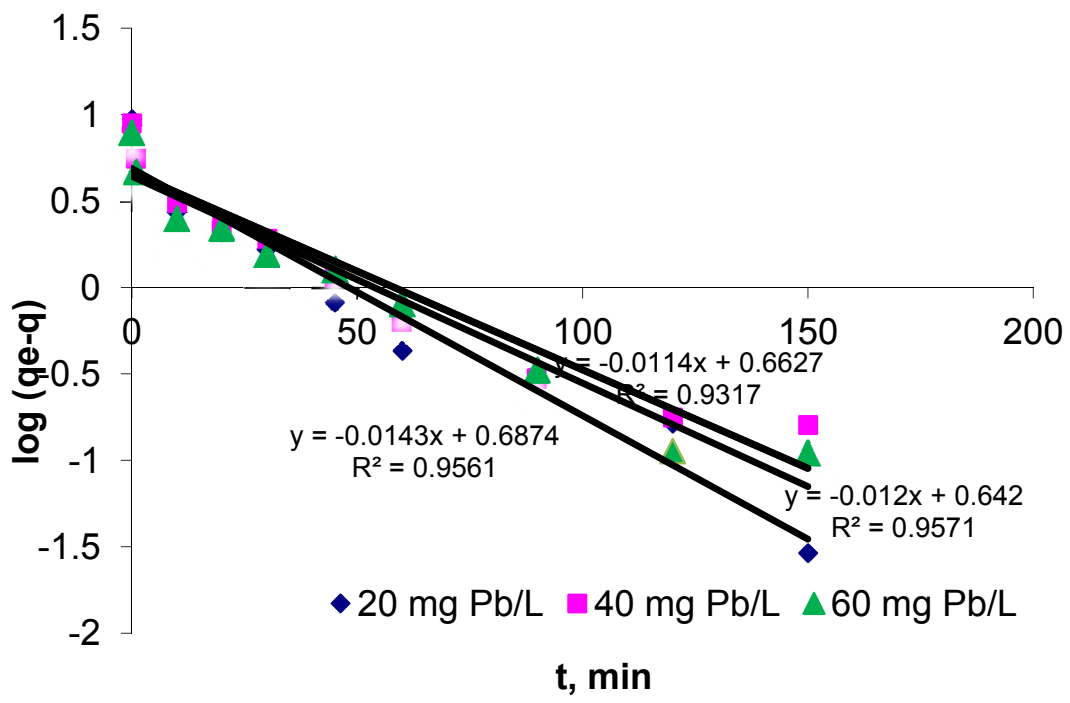

Figure 5: $\quad$ Pseudo first-order kinetic plot for lead adsorption by CCAC.

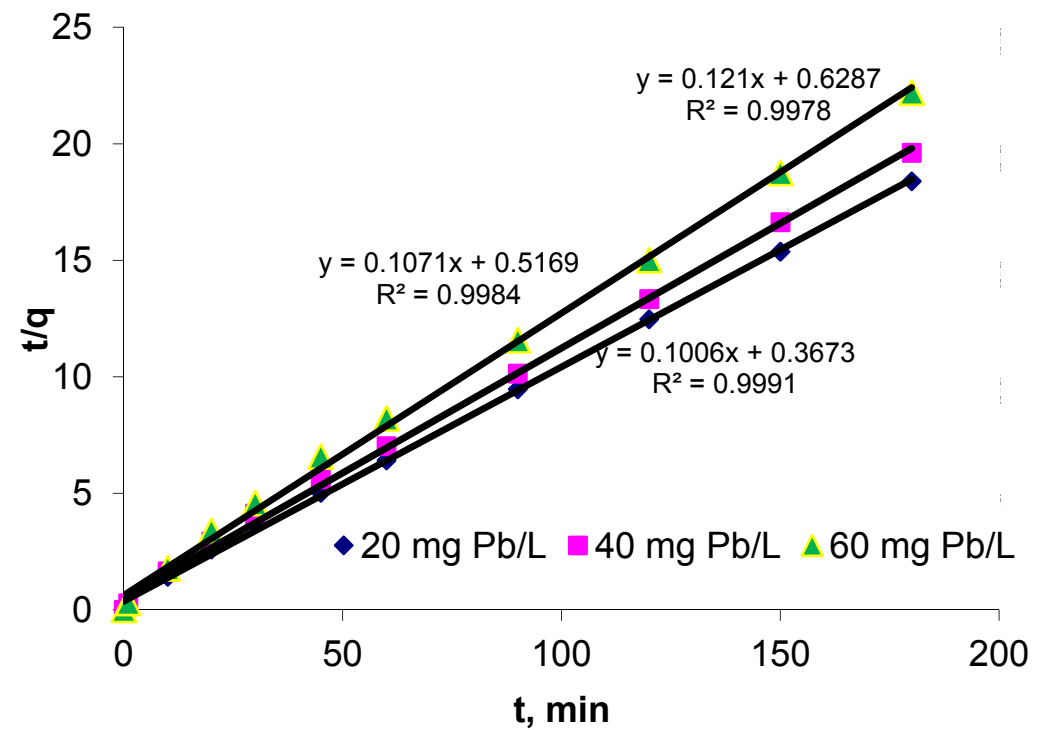

Figure 6: Pseudo second-order kinetic plot for lead adsorption by CCAC. 


\subsection{Adsorption isotherm}

In adsorption in a solid-liquid system, the distribution ratio of the solute between the liquid and the solid phase is a measure of the position of equilibrium. The preferred form of depicting this distribution is to express the quantity $q_{e}$ as a function of $C_{e}$ at a fixed temperature, the quantity $q_{e}$ being the amount of solute adsorbed per unit weight of the solid adsorbent, and $C_{e}$ the concentration of solute remaining in the solution at equilibrium. An expression of this type is termed an adsorption isotherm [13].

The Langmuir adsorption isotherm is

$$
q_{e}=\frac{Q^{o} b C_{e}}{1+b C_{e}}
$$

where, $Q^{\circ}$ is the number of moles of solute adsorbed per unit weight of adsorbent in forming a monolayer on the surface (monolayer limiting adsorption capacity) and $b$ is a constant related to the energy of adsorption.

The Freundlich adsorption isotherm is

$$
q_{e}=K_{f} C_{e}^{1 / n}
$$

where, $K_{f}$ is the Freundlich constant (adsorption capacity) and $1 / n$ represents the adsorption intensity.

Adsorption isotherm for lead adsorption by CCAC and CAC were determined by batch equilibrium test using optimum contact time and $\mathrm{pH}(2.5 \mathrm{~h}$ and $\mathrm{pH} 5)$ for lead adsorption. The isotherms were fitted to the linear form of the Langmuir equation $\left[C_{e} / q_{e}=1 /\left(b Q^{o}\right)+C_{e} / Q^{o}\right]$, fig. 7 and Freundlich equation $\left[\log q_{e}=\log K_{f}+(1 / n) \log C_{e}\right]$, fig. 8. The values of Langmuir constants $Q^{\circ}$ and $b$, and Freundlich constants $K_{f}$ and $1 / n$ are shown in table 3. Values of $Q^{\circ}$ and $K_{f}$ indicated higher lead adsorption capacity of CCAC compared with CAC.

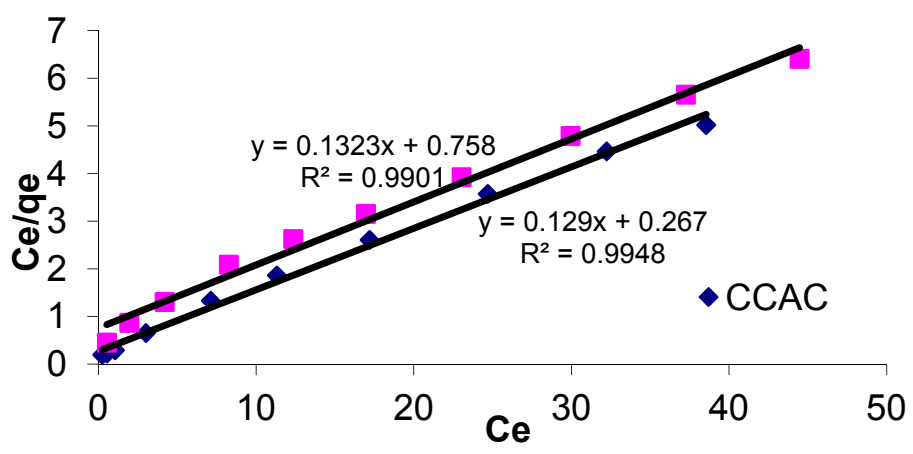

Figure 7: Langmuir adsorption isotherm for lead adsorption. 


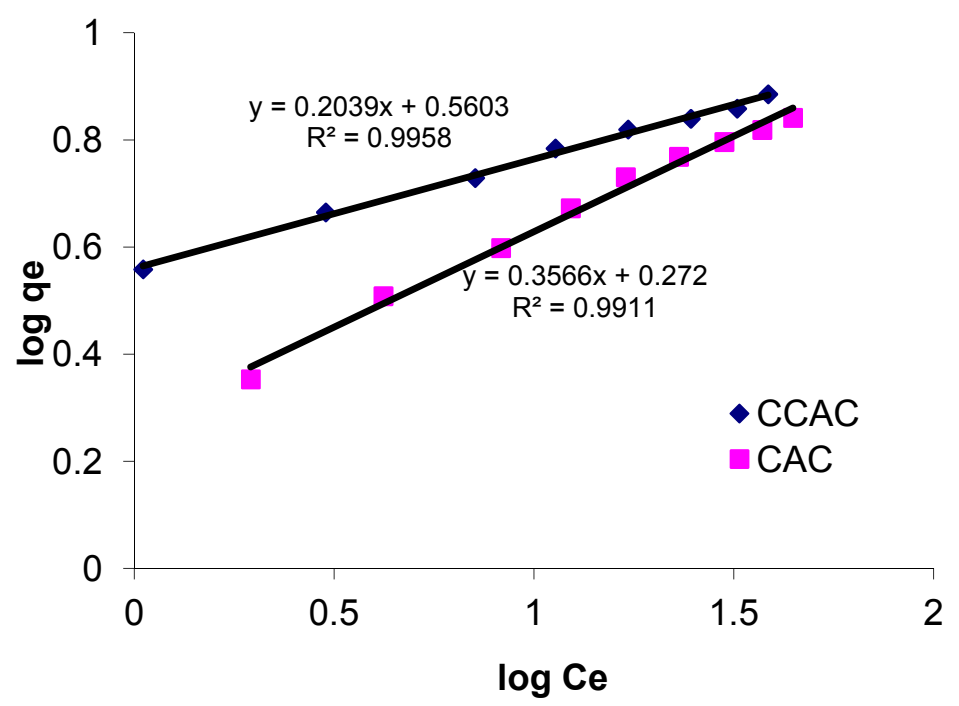

Figure 8: Freundlich adsorption isotherm for lead adsorption.

Table 3: Langmuir and Freundlich constants for lead adsorption.

\begin{tabular}{|c|c|c|c|c|}
\hline \multirow{2}{*}{$\begin{array}{c}\text { Activated } \\
\text { carbon }\end{array}$} & \multicolumn{2}{|c|}{ Langmuir constant } & \multicolumn{2}{c|}{ Freundlich constant } \\
\cline { 2 - 5 } & $Q^{o}$ & $b$ & $K_{f}$ & $1 / n$ \\
\hline CCAC & 7.75 & 0.48 & 3.63 & 0.20 \\
\hline CAC & 7.55 & 0.17 & 1.87 & 0.36 \\
\hline
\end{tabular}

\section{Conclusions}

The coconut coir activated carbon (CCAC) possessed higher surface and micropore areas, micropore volume and average pore diameter, and welldeveloped meso- and micropores compared to those of a commercial bituminous coal-based activated carbon (CAC). Maximum lead adsorption occurred at $\mathrm{pH} 5$ and equilibrium adsorption was attained in $2.5 \mathrm{~h}$. Lead adsorption by CCAC followed pseudo second-order kinetics. The CCAC showed higher lead adsorption capacity compared with CAC. The CCAC is a suitable substitute for commercial activated carbon in the adsorptive removal of lead from water.

\section{Acknowledgements}

The authors are thankful to the management and authorities of the Universiti Teknologi PETRONAS (UTP) and the Civil Engineering Department, UTP for providing facilities for this research. 


\section{References}

[1] Rao, M.M., Ramesh, A., Rao, G.P.C. \& Seshaiah, K., Removal of copper and cadmium from aqueous solutions by activated carbon derived from Ceiba pentandra hulls. Journal of Hazardous Materials, 129(1-3), pp. 123-129, 2006.

[2] Momčilović, M., Purenović, M., Bojić, A., Zarubica, A. \& Ranđelović, M., Removal of lead(II) from aqueous solution by adsorption onto pine cone activated carbon. Desalination, 276(1-3), pp. 53-59, 2011.

[3] Sulaymon, A.H., Abid, B.A. \& Al-Najar, J.A., Removal of lead, copper, chromium, and cobalt onto granular activated carbon in batch and fixed-bed adsorbers. Chemical Engineering Journal, 155(3), pp. 647-653, 2009.

[4] Han, J.S. \& Rowell, J.S., Chemical composition of agro-based fibers. Paper and Composites from Agro-Based Resources, eds. R.M. Rowell, R.A. Young \& J.K. Rowell, CRC Press: Boca Raton, pp. 83-134, 1996.

[5] Conrad K. \& Hansen H.C.B., Sorption of zinc and lead on coir. Bioresource Technology, 98(1), pp. 89-97, 2007.

[6] Standard Methods for the Examination of Water and Wastewater, 21st ed.; American Public Health Association, Washington DC, pp. 3-17-3-19, 2005.

[7] Onundi, Y.B., Mamun, A.A., Al Khatib, M.F. \& Ahmed, Y.M., Adsorption of copper, nickel and lead ions from synthetic semiconductor industrial wastewater by palm shell activated carbon. International Journal of Environmental Science and Technology, 7(4), pp. 751-758, 2010.

[8] Mengistie, A.A., Siva Rao, T., Prasada Rao, A.V. \& Singanan, M., Removal of lead(II) from aqueous solutions using activated carbon from Militia ferruginea plant leaves. Bulletin of the Chemical Society of Ethiopia, 22(3), pp. 349-360, 2008.

[9] Giraldo-Gutérrez, L. \& Moreono-Piraján, J.C., Pb(II) and Cr(VI) adsorption from aqueous solution on activated carbons prepared from sugar cane husk and sawdust. Journal of Analytical and Applied Pyrolysis, 81(2), pp. 278-284, 2008.

[10] Gueu, S., Yao, B., Adouby, K. \& Ado, G., Kinetics and thermodynamics of lead adsorption on to activated carbons from coconut shell and seed hull of palm tree. International Journal of Environmental Science and Technology, 4(1), pp. 11-17, 2007.

[11] Liu, Z. \& Zhang, F-S., Removal of lead from water using biochars prepared from hydrothermal liquefaction of biomass. Journal of Hazardous Materials, 167(1-3), pp. 933-939, 2009.

[12] Hamadi, N.K., Chen, X.D., Farid, M.M. \& Lu, M.G.Q., Adsorption kinetics for the removal of chromium(VI) from aqueous solution by adsorbents derived from used tyres and sawdust. Chemical Engineering Journal, 84(2), pp. 95-105, 2001.

[13] Weber W.J., Jr., Adsorption (Chapter 5). Physicochemical Processes for Water Quality Control, ed. W.J. Weber, Jr., Wiley-Interscience: New York, pp. 199-259, 1972. 